\title{
Single session endoscopic management of intrinsic ureteropelvic junction obstruction and concomitant renal stone disease in a child:
}

a case report

\author{
Murat Ugras*, Ali Gunes, Ugur Yilmaz and Can Baydinc
}

Address: Department of Urology, İnönü University, Faculty of Medicine, 44069 - Malatya, Turkey

E-mail: Murat Ugras* - mugras35@yahoo.com; Ali Gunes - gunesali@yahoo.com; Ugur Yilmaz - uyilmaz@inonu.edu.tr; Can Baydinc - cbaydinc@inonu.edu.tr

${ }^{*}$ Corresponding author

Published: 24 September 2002

BMC Urology 2002, 2:11

This article is available from: http://www.biomedcentral.com/I47/-2490/2/II

C 2002 Ugras et al; licensee BioMed Central Ltd. This article is published in Open Access: verbatim copying and redistribution of this article are permitted in all media for any purpose, provided this notice is preserved along with the article's original URL.

\begin{abstract}
Background: Percutaneous nephrolithotomy is a well known therapeutic modality for stone diseases of childhood. Antegrade and retrograde endopyelotomies are also well defined options of treatment for secondary ureteropelvic junction obstruction. Yet there are few reports regarding endoscopic therapy of intrinsic ureteropelvic junction obstruction. To our knowledge, there exist only a few reports of endosurgical treatment of children with stone disease and with concomitant intrinsic ureteropelvic junction obstruction, in the literature.
\end{abstract}

Case presentation: We present the endoscopic management of stone disease and concomitant intrinsic ureteropelvic junction obstruction of a child in one session.

Conclusion: Percutaneous nephrolithotomy and antegrade endopyelotomy is combined safely with successful outcome in a child.

\section{Background}

Renal calculi of children may be divided into two categories according to the cause: those with an underlying urologic cause and those without. Among the anatomic causes, ureteropelvic junction obstruction (UPJO) is the most common lesion, paralleling that seen in adults [1].

Since renal stone disease of childhood is a recurrent situation, the patient is a candidate for multiple interventions for stone clearance during lifetime. For this reason, care must be taken to be as minimally invasive as possible in the initial therapy without sacrificing the treatment outcomes, and open surgery should be considered as the last choice [2]. Stone disease in childhood is managed with success rates of $83 \%$ to $100 \%$ by percutaneous nephrolithotomy (PNL) $[3,4]$.

Open pyeloplasty remains as the gold standart for treatment of both intrinsic and secondary UPJO [5]. With the advent of equipment and experience, endoscopic procedures are gaining popularity as a treatment option of intrinsic UPJO in children with success rates of $70 \%$ to $88 \%$ [5-8]. Cold knife is thought to be the preferred method of incision because of the risk of secondary scarring due to electrocautery [6].

In a MEDLINE search for a combination of PNL and endopyelotomy in a single session, the authors realised one report of PNL, endopyelotomy and nephropexy in a single 


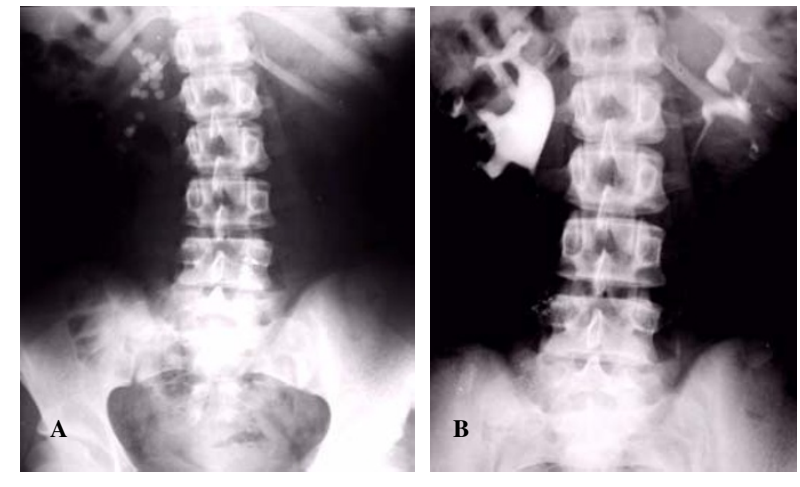

\section{Figure I}

Plain roentgenogram revealing stones in the right kidney $(A)$ and intravenous urogram with suspicion of right UPJO (B).

session of a 47-year-old man, and another report of endopyelotomy and PNL of an 8-year-old child [8,9]. To our knowledge, the presented case is one of the few pediatric cases with intrinsic UPJO that has undergone PNL for stone disease and antegrade endopyelotomy in the same session.

\section{Case presentation}

A 10-year-old girl was admitted with mild right flank pain, nausea and vomiting. In medical history, she had a left ureterolithotomy 7 years ago. The authors were not able to reach any medical records about that operation, and the parents were not informed about any anomaly of the right kidney at that time. She also had some attacks of fever, nausea and abdominal pain in the past, attributed to gastrointestinal infections and treated with antibiotics. No other finding of medical interest was present in family history. There was not any important finding on physical examination but a left flank incision scar. There was right flank tenderness at physical examination. Ultrasonography revealed normal ecogenity, moderate hydronephrosis and multiple stones in the right kidney, with parenchymal thickness of four to seven milimeters. Left kidney was completely normal. On intravenous urography, there were 17 stones inside a dilated right pelvicalyxeal system, the largest being seven milimeters in diameter, and a suspicion of right UPJO (Figure 1). Blood pressure, complete blood cell count, blood biochemistry and urinalysis were within normal limits. No evidence of vesicoureteral reflux was present on voiding cystography. Renal scintigraphy with diethylenetriamine-pentaacetic acid (DTPA) and dimercaptosuccinic acid (DMSA) revealed total and right kidney glomerular filtration rates (GFR) of $59.9 \mathrm{ml} / \mathrm{min}$ and $21.8 \mathrm{ml} / \mathrm{min}$ respectively and minimal to moderate scarring in both poles of the right. Diuretic renogram revealed delayed elimination of the tracer from right kidney (Figure 2). Computed tomography and retrograde study showed no signs of extrinsic cause for obstruction so the UPJO was thought to be of intrinsic origin. Since that she had a previous surgery for a ureteric stone on the left side and only moderate hydronephrosis on the right, she was considered to have a general tendency for stone formation. Furthermore, the degree of the hydronephrosis was not enough to explain the reduced functional share of the right kidney, and the patient could have had some urinary infections contributed to the detoriation of the renal functions and to the stone formation.

After informing her parents on stone disease of childhood, UPJO, current treatment modalities and complications, surgical team and family decided on performing PNL and endopyelotomy. Written consent was obtained for both the operation and publishing of the outcomes.

In the operation, a 6 Fr ureter catheter was placed just distal to the stenotic part and a retrograde radioopaque study was performed, revealing a narrow segment of $1,2 \mathrm{~cm}$ length. The catheter could not be passed into the renal pelvis, but the radioopaque could, through a narrow opening (Figure 3A). In prone position, right lower pole calyx was punctured and dilated to 28 Fr with Amplatz dilators over a 0,038 inches guidewire, and a 26 Fr nephroscope was introduced to the system. Two stones in this calyx and seven located in renal pelvis were grasped with forceps. Another seven stones in different calyces were displaced into the pelvis by forceful irrigation with normal saline injected through a 6 Fr catheter, and then grasped in the same way. There was no evidence of edema or stone obstruction at the UPJ and no need for intracorporeal lithotripsy during the procedure. Efforts to move or grasp one stone of four milimeters inside an isolated lower pole calyx with a narrow infundibulum have failed. Afterwards, the nephroscope was replaced with a 21 Fr urethrotomy sheath with a hooked knife and advanced to the renal pelvis until the UPJ was clearly seen. After placing an antegrade safety guidewire to the ureter, a $1,5 \mathrm{~cm}$ long cold cut incision was made to the ureteropelvic junction and proximal ureter posterolaterally till perinephritic fat was seen. Hemoglobin decrease was $1,2 \mathrm{mg} / \mathrm{ml}$ and there existed no need for transfusion. A 7-14 Fr, $26 \mathrm{~cm}$ double pigtail endopyelotomy stent and a re-entry nephrostomy tube were placed to the ureter and nephrostomy tract, respectively (Figure 3B). Recovery was uneventful. Nephrostomy tube and endopyelotomy stent were removed on fourth and 43rd postoperative days, respectively.

She was followed up monthly with ultrasonography and urine cultures and has undergone metabolic evaluation 


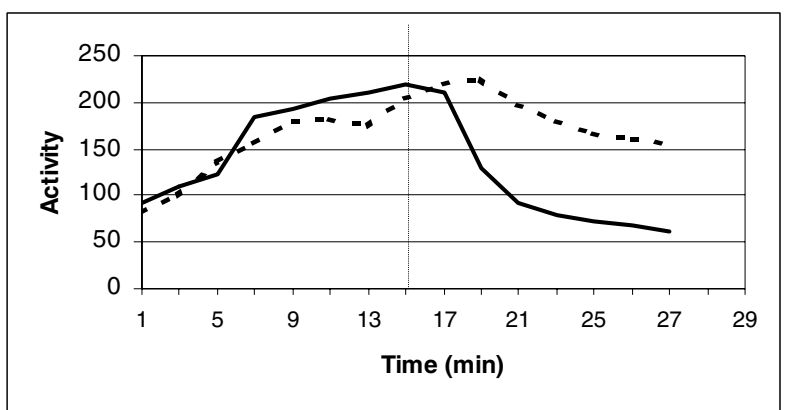

Figure 2

Diuretic renogram studies of the right kidney. Diuretic renograms of the right kidney which were obtained before (dotted line) and 4 months after (straight line) the operation are superimposed in the same graphic for better comparison. Perpendicular dotted line indicates the time of diuretic injection.

which has failed to determine any significant cause for the renal stone disease. Analysis with x-ray diffraction showed that the stones were consisted of calcium oxalate dihydrate.

On the fourth postoperative month, DTPA and DMSA scintigraphy and diuretic renogram was obtained revealing slightly elongated but better elimination of the tracer without any evidence of further scarring of the renal tissue with total and right GFRs of $59.5 \mathrm{ml} / \mathrm{min}$ and $21.2 \mathrm{ml} /$ min, respectively (Figure 2).

The patient is taken to our routine control programme for recurrent stone disease and is undergoing ultrasound, urine culture and urinalysis in every six months.

\section{Conclusion}

Despite a silent residual stone, patient benefit in terms of stone removal and functional correction was satisfactory. Today, there is agreement that a renal pelvis with stones and a suspicion of UPJO should first be freed of stones, as the obstruction may be reactive (that is secondary to the stone) and then re-evaluated for true anatomical UPJO $[10,11]$. Usually six to eight weeks of time is recommended for assesing the UPJ again. We have considered this during the surgery, but since that the stones were no larger than seven $\mathrm{mm}$ in diameter, moving freely inside the pelvis without obstructing the UPJ; since a 6 Fr ureteral catheter could not be passed through the narrow part of the ureter and since there was no evidence of renal pelvic ede-

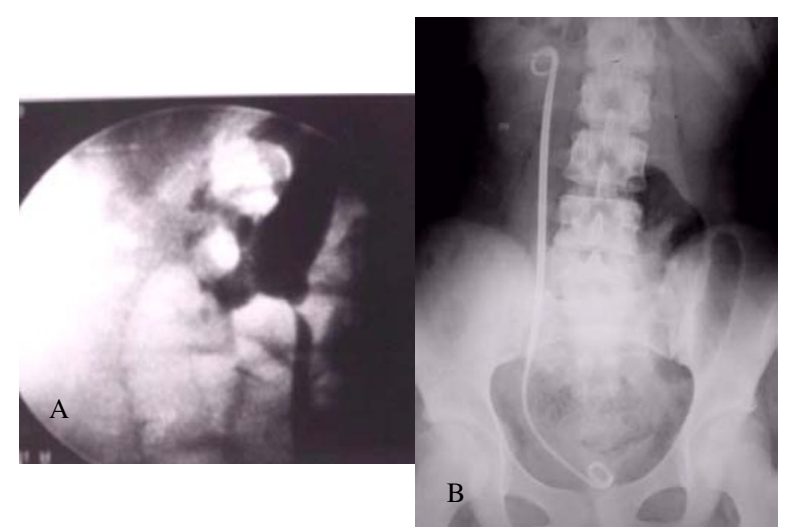

Figure 3

Retrograde ureteropyelography at the beginning of the operation $(A)$ and plain roentgenogram on the $3^{\text {rd }}$ postoperative day (B).

ma with visual control, we decided to go on with endopyeletomy. In our opinion, endoscopical approach seems to be a rational choice in pediatric cases with intrinsic UPJO and concomitant renal stone disease.

\section{Competing interests}

None declared.

\section{Authors contributions}

MU diagnosed the disease, performed the operation, conceived of the study and drafted the manuscript. AG discussed treatment options, guided in the operation. UY participated in drafting of the manuscript. CB participated in manuscript design and coordination.

\section{Acknowledgements}

Written consent was obtained from the patients' family for publication of the study.

\section{References}

I. Menon M, Parulkar BG, Drach GW: Urinary lithiasis: Etiology, Diagnosis, and Medical Management. In: Campbell's Urology (Edited by: Walsh PC, Retik AB, Vaughan ED, Wein AJ) Philadelphia, WB Saunders Company 1998, 2659-2752

2. Tiselius HG, Ackerman D, Alken P, Buck C, Conort P, Gallucci M: Guidelines on Urolithiasis. In: EAU Guidelines (Edited by: Frohneberg D, Hedlund PO, Lobel B, Mandressi A, Parsons K, Rioja Sans LA, Sofras F) 2001

3. Sahin A, Tekgul S, Erdem E, Ekici S, Hascicek M, Kendi S: Percutaneous nephrolithotomy in older children. J Pediatr Surg 2000, 35(9): $1336-1338$

4. Badawy H, Salama A, Eissa M, Kotb E, Moro H, Shoukri I: Percutaneous management of renal calculi: experience with percutaneous nephrolithotomy in 60 children. J Urol 1999, 162(5): $1710-1713$

5. Schenkman EM, Tarry WF: Comparison of percutaneous endopyelotomy with open pyeloplasty for pediatric ureteropelvic junction obstruction. J Urol 1998, 59:1013-1015 
6. Faerber G], Ritchey ML, Bloom DA: Percutaneous endopyelotomy in infants and young children after failed pyeloplasty. $J$ Urol 1995, 154:1495-1497

7. Giusti G, Shalhav AV, Elbahnasy AM, Hoenig DM, McDougall EM, Maxwell KL, Clayman RV: Retrograde vs antegrade endopyelotomy in the treatment of primary and secondary ureteropelvic junction obstruction: The Washington University experience. J Urol 1997, 157:286

8. Tan HL, Najmaldin A, Webb DR: Endopyelotomy for pelvic-ureteric junction obstruction in children. Eur Urol 1993, 24:84

9. Hoenig DM, Hemal AK, Shalhav AL, Clayman RV: Percutaneous nephrostolithotomy, endopyelotomy and nephropexy in a single session. J Urol 1998, I60(3):826-827

10. Motola JA, Badlani GH, Smith AD: Results of $2 \mid 2$ consecutive endopyelotomies: an 8-year followup. J Urol 1993, 149:453-456

II. Danuser H, Ackermann DK, Bohlen D, Studer UE: Endopyelotomy for primary ureteropelvic junction obstruction: risk factors determinate the success rate. J Urol 1998, | 58:56-6I

\section{Pre-publication history}

The pre-publication history for this paper can be accessed here:

http://www.biomedcentral.com/1471-2490/2/11/prepub 